\title{
SOPHÍA/PHILO-SOPHÍA: UNA CIRCULARIDAD QUEBRADA
}

\author{
Francisco SAMARANCH
}

Departamento de Filosofia. UNED

1. Una tradicional -y socorrida - explicación etimológica del término philosophía nos dice que esta significa amor a, búsqueda de, interés por la sophía. Como si esta última, a la manera de experiencias tan inmediatas como el amor, la busca o el deseo, fuera algo tan evidente que todo el mundo debía compartir, la aclaración pone todo el énfasis en la idea de búsqueda. Por supuesto el objeto de tal búsqueda es siempre la sophia y lo único que cambia es la actitud del sujeto que, de receptor y poseedor de un saber indiscutible, pasa a ser un sujeto abierto a la indagación y la justificación de aquello que aspira a saber. No se trata de la legendaria sabiduría de «los Siete Sabios", que más bien encarnan los valores de la época clásica del $\mathrm{s} . \mathrm{v}$-no en vano Aristóteles pudo imaginar a Solón como un representante de lo que entendía por "clase media"1_, sino del fondo más arcaico del saber griego. Ahora bien, al tomar la sophía como algo de suyo evidente, se propician al menos dos desmanes críticos de consecuencias graves: (i) si se pone el acento en la continuidad y se considera que la philo-sophía es lo mismo sólo que con ciertos retoques formales de tinte racionalista, se vuelca sobre la sophta el concepto que la propia philosophia se ha hecho de sí misma; (ii) si, por el contrario, el acento recae en la oposición entre ambas, se achaca a la sophia todo aquello que la philosophia cree ajeno a su propio modo de proceder. La primera opción minimiza de alguna manera sus supuestos racionalistas y los hace extensivos al pensamiento que le precede; la segunda, a la inversa, maximiza la racionalidad estrenada y achaca al pensar mítico hasta sus propias limitaciones o lo que ella misma considera negativo: la «inferioridad" del pensar previo está ya definida.

1 Aristoteles, Politica, IV, 11, 1296a 19. 
Que este «olvido» crítico del enlace que hay entre sophia y philosophia sigue de alguna manera enquistado en la forma en que se abordan los orígenes de la filosofía nos lo confirmarían dos testimonios recientes.

Guthrie, p. e., lo plantea así: «El nacimiento de la filosofía en Europa... consistió en el abandono, al nivel del pensamiento consciente, de soluciones mitológicas para problemas relativos al origen y naturaleza del universo y de los procesos internos a él. A la fe religiosa la sustituye (...) la fe en que el mundo visible esconde un orden racional e inteligible, en que las causas del mundo natural han de ser buscadas dentro de las fronteras de ése, y en que la razón humana autónoma es nuestro único y suficiente instrumento para la investigación" 2 .

El texto merecería, sin duda, una pausada y minuciosa glosa que no podemos hacer aquí. Pero hay al menos dos expresiones que merecen la atención: la de que el abandono de soluciones mitológicas se produce "al nivel del pensamiento consciente", y el de que el cambio de registro pensante se define como un desplazamiento del "objeto de fe o creencia». Incluyendo ahora en ésta tres cosas: que el mundo de nuestra experiencia "esconde un orden (a) racional y (b) inteligible»; que las causas del mundo deben ser inmanentes a él; y "que la razón humana autónoma es nuestro único y suficiente instrumento».

Ahora bien, si el abandono de las "soluciones mitológicas" se produce "al nivel del pensamiento consciente", queda en pie la posibilidad de que esto no ocurra a nivel de un "pensar preconsciente»; pero este es una parte fundamental de nuestro pensar consciente, con lo que la respuesta a tal cuestión puede retrotraer al espacio de la mitología a alguno al menos de los nuevos objetos de la creencia - la existencia de un orden racional e inteligible "oculto", la inmanencia de las causas o la autocalificación de la razón como algo autónomo y suficiente-. La cuestión queda, por supuesto, sin aclarar.

Veamos otro ejemplo. Luc Brisson ${ }^{3}$ escribe que «en la Grecia antigua, hasta Platón, el término sophta puede recibir cualquier contenido en la medida en que la sophia no está vinculada a ningún contenido en el mundo sensiblew. Afirmación sólo cierta con matices: en determinados momentos y contextos tiene un sentido preferencial y muy específico, que intentaremos analizar. Matices que, por otra parte, aun sin haber hecho mención de ellos, parece tener pre-

2 Véase Guthrie, W. K. C., A History of Greek Philosophy, fol. I, Cambridge, At the University Press, 1963 (Repr. 1967), p. 29.

3 Luc Brisson, Mythe et savoir, en BRUNSChwig, J.-Llovd, G. E. R., Le Savoir Grec. Dictionnaire Critique, Flammarion, París, 1996, p. 77. 
sentes Brisson cuando más adelante escribe: «sobre todo no hay que olvidar que la ciencia y la filosofía griega se desarrollaron en un mundo en que los reflejos del pensar tradicional no habían desaparecido del todo" 4 .

Sin embargo, nada se nos dice acerca de ese pensar tradicional ni, sobre todo, acerca de esos "reflejos" - mucho más neuromotores que lumínicos, por supuesto- que perduran en la filosofia.

Estas dos muestras nos indican que, por mucho que formalmente se rechace la fantasiosa teoría de Renan, sistematizada de alguna manera por Burnet, sobre el "milagro griego" -el célebre paso "Del Mito al Logos" 5_, las teorías alternas brillan aún bastante por su ausencia, especialmente en el marco de la historia de la filosofía. Vamos a intentar llenar de alguna manera esa laguna.

2. La historiografía suele colocar bajo el nombre de Cornford un primer intento crítico y razonado de esa concepción de los orígenes de la filosofía 6 . Pero su intento quedó aún corto, en cuanto su explicación del origen de la filosofía se limitaba a "la decantación progresiva del pensar mítico en una conceptualización filosófica" 7 . Ciertamente, se pueden establecer paralelos entre la Teogonia hesiódica y Anaximandro. Pero ¿dónde estaban o cómo se forjaron esos moldes de "conceptualización filosófica" en que se vierte el mito? $\mathrm{Ni}$ los conceptos filosóficos ni el lenguaje que los sustenta nacen armados de la cabeza hirviente de ningún filósofo, trasfundidos a ella desde algún lejano espacio metacósmico. De modo que esa explicación es aún insuficiente, en cuanto no explica cómo se accede a este nuevo modo de pensar, ni cuáles han sido las circunstancias que lo han propiciado, etc. Más aún: la cuestión del hiato cualitativo entre mythos y logos pervive solapada, como da a entender el propio Cornford al declararse deudor de la especulación de Lucien Lévy-Bruhl en el propio prólogo de la obra de $1912^{8}$.

4 BRISsON, op. cit., p. 84.

5 BURNeT, John, Early Greek Philosophy, 1908 (2.a ed.).

6 La obra clave de Cornford es, en este aspecto, Cornford, F. M., From Religion to Philosopby, Arnold, Londres, 1912 [hay traducción castellana: De la Religión a la Filosofia, Ariel, Barcelona, 1984]. La tesis se culmina y amplía en la obra póstuma del mismo autor, Principium Sapientiae, Cambridge Univ. Press, 1952 [traducción castellana, Visor, Madrid 1987].

7 Véase Marcel Detienne, Les maîtres de vérite dans la Grece Archaïque, F. Maspero, París, 1967, p. 100.

8 En el Prefacio - p. 10 de la traducción castellana-y en nota a pie de página, luego de hacer referencia de las deudas contráddas con Émile Durkheim y el círculo de L'Année Sociologi- 
El panorama comienza a cambiar de manera sustantiva a partir de las investigaciones de Louis Gernet y Jean-Pierre Vernant: para entender el humus en que la filosofía como tal puede empezar a germinar hay que analizar un subsuelo mucho más amplio y cercano a la vida cotidiana, a saber, el de los cambios estructurales de la sociedad, de la transformación de la idea de soberanía y el surgimiento del derecho y, por encima de todo, de la laicización del uso de la palabra?.

Dejando para otro lugar, si se tercia, una historia de las transformaciones que sufre la crítica histórica que de ellas se sigue, vamos a tomar como referencia aquí dos líneas de investigación que, aunque parten de perspectivas distintas, tienen importantes puntos de convergencia para nuestro propósito: poner de relieve algunos de los puntos de fractura y de continuidad que enlazan entre si sophia y philo-sophia.

3. Nuestra primera referencia será Giorgio Colli. Colli toma como área de exploración el ámbito de los misterios y el de la mántica. Y, como dioses emblemáticos de ellas, Diónisos y Apolo ${ }^{10}$. La trayectoria que, de alguna manera, sugiere Colli sería esta: la sabiduría es delirio; lo es en Diónisos y lo es, de manera más especifica, en Apolo; ambos son, por añadidura, bivalentes y poseen puntos de convergencia; pero en Apolo la posesión y delirio sapienciales dan lugar a un modo particular de sabiduría: la adivinación; la adivinación se articula en dos tiempos: la posesión de un individuo particular por el dios y la interpretación del mensaje, ya que este se da cifrado; al ser ambos personajes distintos y ser la tarea del intérprete posterior y, en principio, no inspirada, da lugar a la competencia y discusión acerca del sentido: ahí nace la dialéctica. Vea-

que, escribe: "Quiero también expresar mi deuda respecto al libro del profesor Lévy-Bruhl, Les fonctions mentales dans les societés inférieures (1910). ¿Es posible, desde una perspectiva como la que sustenta ese título, salvar el hiato entre mito y filosofía o estamos tan sólo ante otra manera de decir "el milagro"?".

9 Véanse, p. e., Gernet, L., Anthropologie de la Grèce Antique, F. Maspero, París, 1968, en especial el capítulo "Droit et Prédroit» (pp. 153-186 de la versión castellana, Antropología de la Grecia Antigua, Taurus, Madrid, 1981). Vernant, J.-P., Mythe et pensée chez les Grecs, F. Maspero, París, 1965 - 2. ${ }^{2}$ ed. 1969-; nueva edición revisada y aumentada con estudios posteriores, Edits de la Découverte, París, 1988; en especial el capítulo "Aspects mythiques de la Mémoire et du Temps» (pp. 51-94 de la ed. de 1969). También Ramnoux, C., La nuit et les enfants de la nuit dans la tradition grecque, París, 1959.

10 Giorgio Colu, La sagesse grecque [trad. francesa de La sapienza greca, 1977], Editions de l'Éclat, Combas, 1990 (tomo I). [Está en proceso de publicación una traducción castellana de esta obra en Trotta, Madrid.] 
mos primero algunos testimonios acerca de cada uno de esos pasos o momentos.

a) Diónisos. «Con Diónisos la vida aparece como sabiduría, sin dejar de ser la vida temblorosa o agitada: ahí está el secreto" ${ }^{11}$. Uno de los rasgos de esa divinidad es típicamente la globalidad de su campo de referencia: "Diónisos es vida y muerte, alegría y sufrimiento, éxtasis y espasmos, benevolencia y crueldad, cazador y presa, toro y cordero, macho y hembra, deseo y desprendimiento, juego y violencia, pero todo ello de manera inmediata (...), todo ello vivido al mismo tiempo, sin un antes ni un después, y con una plenitud turbadora en cada extremo" ${ }^{12}$. Más aún si cabe: "Diónisos no es un hombre: es, a la vez, un animal y un dios» 13 .

Sin embargo, hay también en él «rasgos que sólo se justifican en la perspectiva del conocimiento». Porque, en el espacio que acotan sus ritos, «el éxtasis no es el objetivo del clímax orgiástico dionisíaco, sino sólo el instrumento de una liberación cognitiva: una vez rota la individualidad, el poseído por Diónisos ve lo que los no-iniciados no ven" ${ }^{14}$. Después de todo, "el resultado de esta manía es una visión, de la misma manera que el apogeo de la iniciación de Eleusis viene dado por la epopteics 15 .

La atribución del poder mántico a Diónisos tiene raíces muy antiguas, de las que aún se hace eco la literatura de los siglos v y IV: "Eso dijo el adivino Diónisos a los tracios", leemos en Eurípides ${ }^{16}$. Y el mismo trágico escribe, en $B a$ cantes:

"Pero ese dios es un adivino: pues lo que es báquico, lo que se muestra delirante, es muy apto para la adivinación. Pues cuando el dios entra con fuerza en un cuerpo, hace vaticinar a los poseídos por el delirio.» 17

11 Colul, op. cit., p. 15.

12 Ibid.

13 Ibid. Nótese el contraste con la ubicación conceptual del hombre en la Politica de ArIsTÓTELEs: el hombre asocial es "o una bestia salvaje o un dios" (I, 2, 1253 a 29; antes, en 1253a 4, se había limitado a decir que era "inferior o superior a un hombre». Estamos claramente en otro modo de pensar: allí, los extremos contrarios se aúnan; aquí, se separan y excluyen.

14 Colli, op. cit., p. 18.

15 Colli, op. cit., p. 19.

16 Hécuba, 1276.

17 EurfPIDEs, Bacantes, 297-301. 
Está claro que esto nos sitúa en el terreno de la ambivalencia. Porque, a su vez, también «Apolo es el dios de la sabiduría de manera explícita y manifiesta. (...) En la esfera arcaica, conocerlo todo... corresponde solamente a la adivinación, y esta es concedida por Apolo. (...) Apolo concede la sabiduría... a un hombre, pero él se mantiene a un lado, él "el dios que actúa a distancia o de lejos" "18. De hecho, la sabiduría que él otorga no es "la mirada que conoce todas las cosas" 19 , sino una sabiduría "hecha de palabras", que son las que le permiten comunicarse con los humanos.

Que hay un punto de tangencia o confluencia entre ambos dioses lo atestigua de manera nítida un conocido pasaje de Fedro: «El hecho es que, entre nuestros bienes, los mayores son los que nos vienen por medio del delirio de que nos dota un don divino... Fue, en efecto, en su delirio como la profetisa de Delfos y las sacerdotisas de Dodona procuraron a Grecia grandes beneficios... He aquí algo que merece la pena presentar como testimonio, a saber que, entre los antiguos, la manía (delirio) no era considerada una cosa vergonzosa, como tampoco un oprobio, ni tan siquiera por aquellos que instituyeron los nombres: de no ser así no habrían asociado este nombre a la más bella de las artes, a aquella por medio de la cual se discierne el futuro, y no la hubieran llamado mani$k e ́$ (arte del delirio). Pero, como quiera que miraban el delirio como algo bello, cuando nace de un decreto divino, crearon esta denominación. Los hombres actuales, en cambio, por ignorancia de lo bello, han introducido una $t$ y la han llamado mantiké (arte de la adivinación)» 20.

Solo en este contexto es posible entender el pasaje que distribuye entre diversos dioses los distintos modos de la posesión: "en cuanto al delirio divino, lo hemos dividido en cuatro secciones que competen a cuatro dioses: la inspiración adivinatoria la hemos atribuido a Apolo, a Diónisos la inspiración iniciática, a las Musas la inspiración poética, la cuarta en fin a Afrodita y Eros..."21. El reparto entre Diónisos y Apolo sólo implica en parte una separación de funciones: el arte del delirio (maniké) es en última instancia arte de la adivinación (mantike).

b) Apolo. Ahora bien, tampoco Apolo es una figura unívoca. Hay igualmente en él un matiz de duplicidad y contradicción, "que aparece en sus atributos dominantes, el arco y la lira". Para comprender esto, Colli nos invita a

18 Colli, op. cit., p. 23.

19 Pindaro, Piticas, 3, 29.

20 Platón, Fedro, 244 a-c.

21 Platon, Fedro, 265b. 
considerar "la acción de la música inspirada por uno y otro dios»: "La lira —o la cítara - hechiza, seduce, subyuga; amansa a las bestias feroces, a los hombres y a los árboles, como se dice del cantor apolíneo Orfeo (...) Mientras que el sonido de la flauta de Diónisos es uuna llamada amenazante que suscita el deliriomm. También es doble la manera en que ambos dioses pueden causar la muerte - después de todo, lo sagrado siempre es una amenaza para el hombre-: "La acción asesina de Apolo se efectúa por medio de la flecha y su trayectoria, manteniéndose el dios separado de su víctima, mientras que Diónisos mata a su presa de manera directa: la golpea con su tirso o la hace pedazos y la devora, la hace entrar en sím 22 .

Ya hemos hecho mención del papel de Apolo como dios de la sabiduría. Apolo, el dios "que ve todas las cosas» —-pasado, presente, futuro-, hace llegar al hombre su sabiduría por medio de la adivinación. Pero esta es también "un instrumento por medio del cual Apolo ejerce su poder. El don es también un dardo. La célebre oscuridad del oráculo pítico lo confirma, y el ejercicio de este poder se hace presente de manera cruel, indirecta, hostil. El dios se sirve de la palabra, de algo que no pertenece a su sabiduría" - que es sabiduría de la mirada--: "Se sirve de la palabra como de un intermediario (...) a fin de suscitar la sabiduría en el hombre». Este tiene que ser alguien dispuesto a la posesión por el dios - la manía es siempre una condición necesaria: recuérdese el texto ya citado de Fedro-. Pero el adivino poseído no comprende la palabra divina que brota de sus labios: esta «sigue siendo la palabra de un oráculo a la espera de un intérprete». Ahí es - nos dice Colli- «donde se sitúa el nacimiento de la razón, que en su primera manifestación se presenta oculta bajo expresiones cerradas, enigmáticas, cercanas aún a la matriz divina, pero que es ya sabiduría individual» 23 . La idea está perfectamente reflejada en Píndaro:

«... Tengo bajo el codo

dardos rápidos en gran número

en mi carcaj,

dirigidos a aquellos que comprenden: pero respecto a todo

necesitan intérpretes. Sabio es aquel que sabe (eidos) muchas cosas

por naturaleza; pero los que han aprendido

como cuervos turbulentos que croan...» 24

22 Colu, op. cit., p. 26.

23 Colli, op. cit., p. 27.

24 Pindaro, Olimpicas, 2, 83-87. 
La diferencia se establece aquí entre dos clases de "conocedores»: los que por naturaleza saben - los «sabios" - son los que "comprenden»; por el contrario, "los que han aprendido" al modo en que los cuervos se alimentan de carroña — ¿no recuerda eso la "polimátheia" denostada por Heráclito?-, quedan excluidos de los dardos apolíneos. Pero, aun en el caso de los primeros, los elegidos del dios, se "necesitan intérpretes"; la sabiduría no viene dada gratuitamente y sin más.

Ahora bien, «a un intérprete de la palabra de Apolo viene a oponerse otro intérprete... La crueldad de Apolo se hace visible: el que nace a la sabiduría no goza de ella; queda cogido en la trampa de un antagonismo temible (la competición por el conocimiento es, en Grecia, el combate supremo)" 25.

Para no alargarnos más, un texto de Platón nos puede dar una visión de conjunto de lo que era conocimiento en tiempo de «los sabios»:

"Una sola prueba basta para mostrar que el dios ha dado la adivinación a la irracionalidad humana: ningún hombre, en efecto, en estado consciente entra en contacto con la adivinación inspirada por un dios y verdadera, antes bien es preciso que la potencia de su mente esté impedida por el sueno o la enfermedad, o que esté enajenado por alguna posesión. Por el contrario, pensar sobre las cosas dichas, en sueño o en estado de vigilia, bajo la influencia adivinatoria y entusiástica, una vez recordadas, es propio del hombre consciente, lo mismo que discernir con el razonamiento todas las visiones percibidas entonces, ver dónde esas cosas adquieren sentido y para quién pueden representar un mal o un bien futuro, pasado o presente; en cuanto al que está en trance y permanece en él, no le corresponde a él juzgar sobre sus visiones y las palabras que él ha pronunciado.... 26

El conocimiento viene del dios al adivino poseído por él y este lo expresa en palabras. Pero esas palabras no son transparentes: el poseído no es capaz de entender la información transmitida; es un mero resonador de un mensaje que él mismo no está capacitado para descifrar. El mensaje, en efecto, se da cifrado, no tanto porque la verdad del dios sea excesiva para el hombre, sino porque los humanos no deben acceder a la verdad más que parcialmente y con esfuerzo. Por este motivo "la ley ha instituido el linaje de los profetas como intérpretes de las visiones adivinatorias inspiradas por el dios» 27. De alguna manera, pues, "para

25 Colli, op. cit., p. 27.

26 Platón, Timeo, 71e-72a.

27 Platon, Timeo, 72 a-b. 
que lo divino pueda desplegarse en el hombre, es necesario el recurso a la razón, a la explicación, a la argumentación y la aplicación. Tal es la relación natural entre el delirio y la razón, en la que la segunda está subordinada al primero» 28 . La mirada del dios que "todo lo ve" sólo puede ser transferida al hombre en forma de enigma a descifrar. $Y$ eso es lo que nos confirma la concepción antigua del "enigma».

c) Enigmas. Como hemos visto, la revelación de Apolo nunca es directa y transparente: es un mensaje a descifrar. "Restringida a la esfera de la palabra, la sabiduría se revela como un reto del dios: lo que Apolo sugiere no es ni mucho menos un conocimiento luminoso, sino una tenebrosa lacería de palabras. Ahí anida la sabiduría» 29 .

Este maridaje entre el saber y lo cifrado tendrá entre los griegos una larga historia, y no será disuelto del todo ni aun en los momentos de racionalidad más acendrada como veremos. Por lo demás, en el aura de la leyenda, la ignorancia reconocida y puesta en evidencia puede causar la muerte. Estrabón cuenta una historia que dice tomar de Hesíodo: cuando Calcas, el adivino homérico, regresaba de Troya, se encontró en Klaros con Mopsos, hijo de Mantó la hija de Tiresias, y decidió poner a prueba sus capacidades de videncia preguntándole a éste el número de higos que tenía una pequeña higuera silvestre. "Su número es de diez mil y su medida es un medimno", contestó Mopsos. Una vez que se comprobó que la respuesta era exacta, «el sueño de la muerte oscureció a Calcas" 30 . Y un fragmento de Aristóteles nos cuenta la historieta de Homero a que alude Heráclito en el célebre fragmento contra "el más sabio de los griegos» que, sin embargo, no solucionó el acertijo de los jóvenes de los ${ }^{31}$. "Homero consultó al oráculo para saber quiénes eran sus padres y cuál era su patria; y el dios le respondio ast: 'La isla de fos es la patria de tu madre y ella te acogerá [cuando hayas] muerto; pero guárdate del enigma de los jóvenes. Algo más tarde... partio hacia los. Alli, sentado sobre una roca, vio que unos pescadores se acercaban desde la playa y les pregunto si habian cogido alguna cosa. Estos, que, por no haber cogido nada, se habian estado despiojando... Le dijeron: 'Lo que hemos cogido, lo hemos dejado; lo que no hemos cogido, lo llevamos con nosotros', aludiendo, mediante un enigma, a que se habian desembarazado, una vez muertos, de los piojos que habian

28 Colu, op. cit., p. 379.

29 Colu, op. cit., p. 47.

30 Estrabón, 14. 1, 27. Hesfodo, Fr. 278 Merkelbach-West.

31 HerÁlito, Fr. B 56, DK. 
cogido, mientras que llevaban consigo los que no habian podido coger. $Y$ no habiendo sido capaz de solucionar el enigma, Homero murió descorazonado» 32 .

Sin duda, lo primero que llama la atención en ese relato es la desproporción entre lo fútil del contenido del enigma - acertijo ya, de hecho- y el desenlace a que lleva el fracaso en su solución. Pero, para el sabio, un enigma es un desafio a muerte. Quien pretende descollar por las cosas de la inteligencia debe mostrarse invencible en lo que a esta atańe. Por supuesto, aquí ha desaparecido todo trasfondo religioso y oracular; pero aun así el enigma sigue teniendo un papel crítico en el espacio de la competición humana por el saber. Ya desacralizado, el enigma será definido por Aristóteles como "la formulación de una imposibilidad racional que expresa, con todo, un objeto reals, 33 .

Todavía los neoplatónicos creerán que «la expresión enigmática es una característica que se encuentra a menudo en la filosofía, y que se acentúa en dirección a los orígenes» ${ }^{34}$. Proclo, p. e., escribió que «la exposición de Platón no es hasta tal punto enigmática como la de Ferecides»35. El saber, aun fuera de lo oracular e inspirado, no pertenece al orden de lo inmediato: requiere un esfuerzo de la razón. Este sería el punto de llegada de la vía que traza Colli. Queda, sin embargo, mucho por dilucidar aún: ¿qué es lo que propicia esa racionalización y laicización del oráculo y el enigma?

4. Para ver de ceñir algo más el problema, vamos a acudir a M. Detienne ${ }^{36}$. Junto al saber o "verdad" del adivino - cuya vinculación a Apolo hemos visto de la mano de Colli-, hay que colocar la "Verdad" del poeta y la del Rey de Justicia. Comencemos por el poeta.

a) Fiel a la tradición que le precede, Hesíodo recibirá su saber de las $\mathrm{Mu}$ sas ${ }^{37}$, que reivindican para sí la capacidad de "decir cosas verdaderas", de manifestar "lo que es, lo que será, lo que fue» 38 . Estas y no otras son las palabras de la Memoria. Pero esta verdad tiene, al mismo tiempo, en el contexto de Hesíodo, dos registros de referencia: por una parte, hay que ver en él «el único y último

32 Fr. 8, Sobre los poetas, Ross. Ps. Plutarco, Vita Homeri, 3-4.

33 ARISTOTEles, Poética, 22, 1458 a $25 \mathrm{~s}$.

34 Colli, op. cit., p. 433.

35 Proclo, In Platonis Timaeum, 23 c (I, 129, 15-16 Diehl).

36 Dentenne, M., Les maîtres de vérité dans la Grèce Archaique, F. Maspero, París, 1967.

37 Recuérdese el texto de Fedro, 265b (citado antes, $3 \mathrm{c}$ ).

38 Hesiodo, Teogonia, 28 y 32-33, respectivamente. 
testigo de una palabra cantada que se dedica a la alabanza del personaje regio, en una sociedad centrada en la soberanía (...) Pero este personaje no es más que Zeus. A este nivel, el poeta es ante todo un "funcionario de la soberanía»: recitando el mito de emergencia, colabora directamente a la puesta en orden del mundo" 39. Por otra parte, la palabra poética tiene también como misión la alabanza de las hazañas guerreras de los humanos, de modo que "por medio de su alabanza, el poeta concede, al hombre que carece de ella, una "memoria" 40 .

Hay que tener presente, así mismo, que «el campo de la palabra poética está equilibrado por la tensión de una serie de potencias que se corresponden dos a dos: por un lado la Noche, el Silencio, el Olvido; por el otro, la Luz, la Alabanza, la Memoria» 41. De modo que "la triple oposición de Memoria y Olvido, Elogio y Censura [o Silencio], Luz y Noche, dibuja de manera muy precisa la configuración que confiere a Alétheia su significación. (...) Alétheia no tiene una función distinta de Memoria (...) En términos formales, Alétheia se opone a Léthe lo mismo que se opone a Mômos [censura]". Y, en consecuencia, «el poeta es capaz de ver a Alétheia, es un "Maestro de Verdad" "42.

b) La figura de Nereo, "el Viejo del Mar» ${ }^{43}$, nos situará ante una tercera modalidad del «Maestro de Verdad»: «la "Verdad» del Viejo del Mar parece cubrir un doble dominio: mántica y justicia» 44 . Las relaciones entre mántica y Alétheia nos son ya conocidas. Y los poderes mánticos de Nereo están atestiguados en la literatura más antigua: «en la TEOGONÍA hesiódica, Nereo es un justiciero. Pero, para toda una tradición, encarna una potencia mántica cuya sabiduría han exaltado siempre los antiguos y cuyos "dichos" han transmitido cuidadosamente» ${ }^{45}$. ¿Cómo entra en juego aquí la justicia? Los procedimientos judiciales a que el Viejo del Mar apela son "formas de adivinación"; se trata de "una justicia del mar... de carácter ordálico, que pertenece al pasado más remoto de las civilizaciones mediterráneas" 46 . Y a esa justicia basada en una "ordalía de las aguas", hay que añadir la "ordalía por medio de la balanza» 47 . En esa fi-

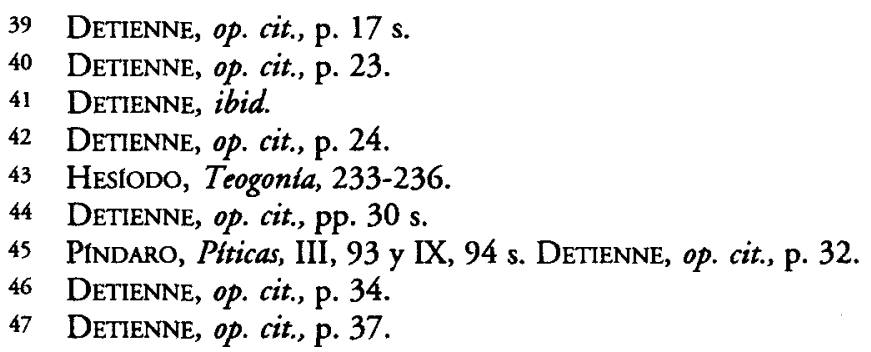


gura mítica - lo mismo que en reyes igualmente míticos como Minos- «convergen las dos formas de justicia, por medio del agua y por medio de la balanza, situadas ambas bajo el signo de Alétheia 48.

Así, pues, «tras el Viejo del Mar (...) detrás de Minos (...), se descubre un tipo de hombre: el personaje regio, provisto de un don de videncia». Pero "la Alétheia del Viejo del Mar no es una "verdad" de tipo histórico. (...) Las "pruebas» de la justicia son de carácter ordálico; es decir, no hay rastro de una noción positiva de la prueba; someterse a juicio es entrar en el dominio de las fuerzas religiosas más temibles" 49 .

c) Intentemos un paso adelante: «en el pensamiento arcaico cabe, pues, distinguir tres dominios: poesía, mántica y justicia, que corresponden a tres funciones sociales en las que la palabra ha jugado un papel importante antes de llegar a ser una realidad autónoma, antes de que se elabore, en la filosofía y la sofística, una problemática del lenguaje» ${ }^{50}$. ¿Cuál es entonces en ese medio el estatuto de la palabra? Y ¿cómo se configura Alétheia en relación a ésa?

En primer lugar, la palabra no es algo situado al margen de las cosas y las acciones; forma parte de un comportamiento que es simultáneamemnte gestual y eficaz. Es una palabra «efectiva" a la que se oponen las palabras ineficaces, las épé akráanta, palabras vanas e inútiles. "La palabra del poeta no busca en ningun momento el acuerdo de los oyentes, el asentimiento del grupo social", y así mismo la del Rey de Justicia "se despliega con la majestad de una palabra oracular" 51. Peitho no es todavía la capacidad de persuasión razonada: es "el encantamiento de la voz, la seducción de la palabra, la magia de los términos» 52 .

Por otra parte, "de hecho, no hay Alétheia sin una parte de Léthes 53 . Ese Olvido no es el Olvido-Muerte, Thánatos, sino su gemelo, el Olvido-Sueño, Hypnos. No hay, pues, "por una parte Alétheia $(+)$ y por otra parte Léthe $(-)$, sino que entre estos dos términos se expande una zona intermedia en que Alétheia se desliza hacia Léthe y a la inversa. La «negatividad" (...) orla la «Verdad», es la sombra inseparable de ella" 54 . Y esas franjas de Léthe que orlan la "Verdad" van

DETIENNE, op. cit., p. 39.

DetIENNE, op. cit., p. 48.

DETIENNE, op. cit., p.

DeTIENNE, op. cit., p. 59.

DETIENNE, op. cit., p. 63.

DeTIENNE, op. cit., p. 69.

DETIENNE, op. cit., pp. $71 \mathrm{~s}$. 
acompañadas de Apáte, engaño: la ambigüedad afecta aun a los dioses más positivos, $\mathrm{y}$ "las Musas y la Memoria pueden ser tales para uno, y Olvido y Silencio para otro"55. Así, pues, "el "Maestro de Verdad" es también un maestro de engaño. Poseer la verdad es también ser capaz de engañar; y las potencias antitéticas Alétheia y Léthe no son contradictorias: en el pensamiento mítico, los contrarios son complementarios" 56 . Así, ni más ni menos, lo entendía el «sabio» Heráclito: "conexiones, totalidades-no totalidades: convergente-divergente, consonante-disonante..., de todas las cosas una sola, y de una sola todas" 57 . Nos movemos, pues, en una lógica de los contrarios en la que es esencial la ambigüedad. $\mathrm{Y}$ usi encontramos en Hesíodo una especie de traducción conceptual de la ambigüedad, es porque la ambivalencia comienza a "ser problemática" en un pensamiento que ya no es mítico y no es aún racional» 58 .

d) Pero no es eso todo. Existe, desde épocas prácticamente arcaicas -el testimonio de la Ilíada es aquí esencial - un importante núcleo social que escapa al dominio de la palabra mágico-religiosa: es el grupo social constituido por los profesionales de la guerra. En este contexto, la palabra accede a una dimensión de diálogo y de intercambio de puntos de vista, quedando sometida a la ponderación de las razones que la sustentan; y esas proceden de la prudencia humana y afectan al comportamiento colectivo: es una palabra básicamente laica. El espíritu de solidaridad comunitaria que es su referente esencial se hace patente en tres prácticas institucionales vinculadas al modo de guerra heroico: los juegos funerarios, el reparto del botín y las asambleas deliberativas; y queda incluso reflejado en la configuración emblemática de su espacio escénico: el círculo. Los premios para los juegos y el botín a repartir son colocados «en el centro", porque "colocados "en el centro", los bienes de Aquiles... vienen a ser "objetos comunes" "59. De manera análoga, "tomar la palabra implica dos comportamientos gestuales: avanzar hacia el medio, por una parte, tomar el cetro en sus manos, por la otra" 60 . Sin duda, este ritual tiene aún sus ambivalencias: la toma del cetro y la ubicación centrada implican el acceso a un espacio "diferenciado" y a un revestimiento de autoridad que le viene al individuo "desde

55 Plutarco, De e apud Delphos, 394 A, ed. F. C. Babbitt, Loeb Class. Libr., repr. 1984.

56 DeTIENNE, op. cit., pp. $77 \mathrm{~s}$.

57 Heráclito, Fr. B 10, DK. Reproduzco la traducción de A. Bernabé en Alianza Editorial, De Tales a Demócrito, 1988.

58 Detienne, op. cit., p. 79.

59 Detienne, op. cit., p. 87.

60 DeTIENNE, op. cit., p. 89. 
fuera" ${ }^{61}$. Pero aun así se trata de una "segregación" transitoria, a la que tienen acceso, por turnos, todos y cada uno de los miembros de la asamblea. La palabra que cada uno pronuncia queda, por tanto, sometida a la contrastación y deliberación: es fundamentalmente una palabra humana y laica. "Ahí es donde se prepara el futuro estatuto de la palabra jurídica o de la palabra filosófica, de la palabra que se somete a la "publicidad» y que obtiene su fuerza del asentimiento de un grupo social» 62 .

La afirmación de Detienne es prudente: "ahí se prepara». Nada más. Estamos ante indicios, vectores que apuntan a algo; tanto más fáciles de interpretar cuanto que conocemos ese "algo" cuyo origen precisamente queremos descifrar. De hecho, sin embargo, esta es aún tan sólo una asamblea de áristoi, y de ella está excluida el démos. la extensión de la palabra-diálogo al pueblo o, al menos, a la totalidad de los "ciudadanos", deberá pasar por otras transformaciones sociales y colaterales -entre ellas, p. e., la sustitución de la "guerra de los héroes" por la "guerra de los hoplitas", y de la pérdida de eficacia de la primera y la necesidad de estrategias alternativas que garanticen el éxito-. Ciertamente no son las "ideas" las que provocan por sí mismas los cambios: "la historia de las ideas no es nunca "su propio principio de inteligencia". Para que emerjan tales cuestiones... es preciso que se haya consumado la ruina de un sistema de pensamiento..." 63. $\mathrm{O}$, al menos, atemperando la formulación de Detienne, es preciso que un sistema de pensamiento empiece a hacer aguas en la vida práctica, que se muestre inadecuado y aun molesto a la hora de afrontar las crecientes complejidades de la sociedad y la vida y provoque una cascada de pequeños ajustes que acaben por vaciarlo de sentido: las causalidades lineales apenas tienen cabida en el espacio de la cultura, los valores, las creencias.

5. Antes de aventurar un paso más en esa búsqueda de una explicación plausible del paso de la sophía a la philo-sophia, veamos dónde nos ha situado el camino recorrido hasta ahora.

Colli ha partido del entorno de la mántica. Esta se mostraba como sabiduría vital y desbordada en el dominio dionisíaco —Diónisos podía expresarse co-

61 Cuando el Rey de Justicia sostiene el cetro, y precisamente en virtud de la fuerza sagrada que emana de este, emite themistás, decretos o veredictos que tienen valor de oráculos, pues el término significa por igual palabra de justicia que palabra oracular de Apolo. Y las funciones de la diosa Themis van de la mántica al derecho y la justicia. Ver DetienNE, op. cit., p. 43.

62 DETIENNE, op. cit., p. 94.

63 Detienne, op. cit., pp. $79 \mathrm{~s}$. 
mo humano, como dios y como bestia-; una sabiduría que era toda proximidad e inmediatez. La mántica, con todo, se vinculaba institucionalmente a Apolo y en ese contexto mostraba otra cara: la sabiduría se hacía ahora mediata y potencialmente racional. Seguía presente en Apolo la doble valencia de lo divino: la capacidad de enseñar y la de destruir. Pero la verdad que este posee, la verdad del que «lo ve todo", es transformada en una verdad sólo audible. Más aún: se articula en dos tiempos, ya que el que recibe los sonidos que la constituyen no es el que va a buscarle su sentido oculto. Cuando ser intérprete de esa verdad se hace objeto de competencia por el prestigio que tal cosa aporta, se está abriendo el campo de la dialéctica. En esta antesala juega un papel clave la institución del «enigma». Y la conexión entre "enigma" y dialéctica podía incluso rastrearla Colli en una rica serie de textos de la propia filosofia ${ }^{64}$.

Para Detienne son tres los registros de la cultura arcaica en que se encuentra formulada la cuestión del «saber» o "la Verdad»: el de la mántica, el de la poesía, el de la justicia. En todos ellos cabe detectar tensiones implícitas de "disolución», especialmente en la medida en que se encuentran las palabras de esos registros están puestas al servicio de instituciones sociales y núcleos de poder - cantan, en efecto, las hazañas de los héroes, los guerreros y los atletas, o imparten justicia- Asimismo, en todos ellos detectamos la ambivalencia de la contrariedad: Alétheia aparece siempre orlada por Léthe -el olvido-y Apáte -el engaño- Las propias Musas no le ocultan a Hesíodo que "saben decir multitud de cosas engañosas» lo mismo que, cuando quieren, "cosas veridicas», y es una y la misma la diosa que va a mostrar a Parménides la vía de la verdad y la de la opinión ${ }^{65}$. Los oráculos, pues, deben ser tomados con reservas. La poesía puede dar "memoria" a los que no la tienen; pero también puede negársela. Y ¿qué valor puede asignarse a una justicia ordálica y mántica, si los oráculos son ambivalentes? La propia Atenea se va a hacer portavoz de esa reticencia: "con juramentos no triunfa la justicia» 66 .

Será, pues, en última instancia, la ambigüedad de la palabra, el claroscuro de la Verdad veteada de Olvido y Engaño, la que habría de provocar una reflexión sobre el lenguaje como instrumento; una reflexión que, estableciendo una distancia entre la verdad y las palabras, situara aquella en otro registro menos lábil. Que la interpretación de los oráculos derivara en competición entre adi-

64 Colli, op. cit., pp. 360-369.

65 Hestodo, Teogonía, 27-28. PARMénides, Fr. 1 DK.

66 ESQUILO, Euménides, 432. 
vinos - antesala de la dialéctica, según Colli- presupone lo que precisamente había que explicar: por qué y en qué contextos el adivino pasa a basar su autoridad en su agudeza mental y ya no en su selección - por linaje, ceguera, etcmilagrosa por algún dios. Es decir, por qué el oráculo degeneró en enigma, antecesor del mero acertijo, figura secular de la simple ingeniosidad humana. Y lo mismo en el campo de la justicia ordálica: lo que hay que explicar no es tanto lo que el corifeo de las EUMÉNIDES contesta a Atenea - "entonces realiza tu investigación y pronuncia un juicio recto» ${ }^{67}$, cuanto por qué, un poco antes, Orestes ha llegado a ser capaz de plantar cara a las Erinias, diciéndoles que "instruido en la desgracia, sé muchos ritos de purificación, y [sé] cuándo se ha de hablar y cuándo callar; $y$ en este caso, he recibido de un sabio maestro la orden de levantar la voz» 68 .

¿Es realmente la potencial ambigüedad de la palabra mágico-religiosa la que provoca la reflexión sobre el lenguaje como instrumento? ¿ $\mathrm{O}$ es más bien la pérdida efectiva de esa ambiguiedad por motivos no racionales la que provoca el malestar? En el veredicto ordálico y en la interpretación del oráculo, la palabra pierde, por hipótesis, su presunta y genérica ambigüedad. Y esto es - no la ambigüedad en sí- lo que provoca la rebelión de Orestes y la sentencia de Atenea: si algo debe zanjar la ambigüedad son razones, no juramentos. Entonces sí, ciertamente, la palabra pierde su dimensión sacra y se hace laica, racional, humana.

Pero, con esto, Detienne explica sólo una parte de lo que su tesis pretendía. ¿Qué pasa - se pregunta - con el contenido semántico de Alétheia, cuando la palabra se hace laica? "La respuesta no puede ser unívoca, ya que el pensamiento griego ofrece dos soluciones, antitéticas en un plano, complementarias en otro. Dos soluciones: la de las sectas filosófico-religiosas, la de la Sofística y la Retórica. Antitéticas: las primeras ponen en el centro de su pensamiento a Alétheia, que viene a ser la noción cardinal, mientras que las segundas privilegian a Apáte, que juega en su pensamiento el mismo papel capital. Complementarias: las condiciones en que Alétheia, en un caso retrocede, se funde, desaparece $y$, en el otro, se mantiene, se afirma, se consolida, ofrecen una prueba en algún grado experimental de que Alétheia es realmente el centro de una constelación de potencias religiosas que tienen entre sí relaciones necesarias" 69.

\footnotetext{
67 Euménides, 433.

68 Op. cit., 276-279.

69 DetIEnNe, op. cit., p. 103.
} 
Tal vez, con todo, las cosas sean algo menos esquemáticas y rígidas. Por de pronto nos faltan aún las mediaciones. Comencemos por ahí.

6. La vía que lleva a la sofística la encuentra Detienne en la figura de un poeta a caballo entre dos modos de vida y sociedad: Simónides de Ceos. En una vida que abarca aproximadamente desde la mitad del s. vi a la mitad del s. $v$, Simónides hace las veces de eslabón en esa genética del pensar sofístico. Y ello por las siguientes razones: *es el primero que hace de la poesía un oficio remunerado; *esa profesionalización del quehacer poético se acompaña en él de una cierta reflexión sobre el propio arte de la poesía: Plutarco le atribuye la afirmación de que "la pintura es una poesía silenciosa y la poesía es una pintura elocuente» 70 - teoría que ha sido, además, relacionada a menudo con el arte de la apáte tal como lo entiende Gorgias-; *se le atribuye, finalmente, el descubrimiento y desarrollo de ciertas prácticas mnemotécnicas. Ahora bien, upracticar la poesía como un oficio, definir el arte poético como una obra de ilusión (apáte), hacer de la memoria una técnica laicizada y enseñable, rechazar la Alétheia como valor cardinal...» son actitudes que nos sitúan en las antípodas del papel arcaico de la poesía. De esta manera resulta evidente que, «segregada de su fundamento, la Aletheia resultaba brutalmente devaluada; Simónides la rechaza como símbolo de la antigua poética. En su lugar reinvindica tò dokein, la doxas ${ }^{71}$.

No nos precipitemos con todo: esa no es la Alétheia de los filósofos, sino la de los poetas; y tampoco es la de Parménides o Platón la doxa de Simónides. Se trata más bien de la sustitución de la urevelación poética» —que provenía de las Musas y la Memoria - por un saber hacer, técnico y humano, que busca la fascinación del oyente por medio de una palabra sabiamente manejada. Una palabra que es entonces portadora de un cierto valor inmanente, y determina que lo ambiguo no sea ya kuna cara de Alétheia. (...) [que] no es ya más la unión de los contrarios, sino la síntesis de contrarios "contradictorios" "72.

En cambio, las sectas filosófico-religiosas prolongan de alguna manera el pensamiento arcaico. En un pequeño tratado de Plutarco ${ }^{73}$, Cleómbroto des-

70 LESKY, A., Historia de la Literatura Griega, trad. castellana Gredos, Madrid, 1968, p. 217.

71 DETIENNE, op. cit., p. 111.

72 DetienNe, op. cit., p. 124.

73 Plutarco, De defectu oraculorum, 422b, ed. de F. C. Babbitt, Loeb Class. Libr., repr. 1984. 
cribe una «llanura de la Verdad» situada en el centro de los ciento ochenta y tres mundos que, en forma de triángulo, constituyen el todo. En un escrito en que abundan las citas de Platón y los ecos claros de Fedro, el texto nos une aún la visión de la Verdad con el espacio de la Memoria. Su tono es decididamente oracular. Este sería, pues, uno de los rasgos más tenaces de la vertiente filosofico-religiosa que señala Detienne. Pero, hay que notar al mismo tiempo que, en la llanura de la Alétheia, esta aparece ahora ya segregada de Peithó, la persuasión, que ahora se sitúa del lado de la Léthe y en oposición a aquella: «el universo espiritual de las sectas filosófico-religiosas es un mundo dicotómico en el que la ambigüedad ha cedido su lugar a la contradicción» 74 . Es decir, en este modo de pensamiento, «sea ella Léthe, Peithb, Apáte o Dóxa, la ambigüedad es siempre lo contrario de Alétheia. No hay tercera vía: es Alétheia o Apátes 75 . Ha entrado, pues, en juego la dialéctica de los contrarios en la perspectiva del principio de no-contradicción y tercero excluido. Y esta era una opción claramente vinculada a una reflexión sobre los condicionantes del lenguaje visto como sistema de comunicación.

Pero, ¿es eso ya la "filosofía», toda la "filosofía»? ¿Significa esto que la filosofía se queda como a mitad de camino en la laicización del pensamiento? La exposición de Detienne se queda ahí corta. Como se quedaba corta y resultaba muy parcial la de Colli. $\mathrm{X}$, sin embargo, la larga indagación que precede no es inútil. Tal vez se trate tan sólo de atar cabos sueltos y cambiar de perspectiva.

7. La proximidad entre Simónides y la sofística resultaba más directa: después de todo Simónides muere sobre el 468 a. de C. y Protágoras había nacido en torno al 485 a. de C. A su vez, el primer uso atestiguado del término philósophos se encuentra en un fragmento de Heráclito, a comienzos del s. v; pero el sentido del término sólo adquiere consistencia en el contexto que delimitan Platón y Aristóteles. "Philosophía" es, pues, un término con fecha de nacimiento.

En el marco que dibuja Detienne, sin embargo, quedan fuera de ubicación los Milesios, fueran o no propiamente filósofos - aunque ¿quién decide qué es ser "filósofo"?- - Y quedan obliteradas las conexiones entre sofística y filosofía en el espacio que inaugura Sócrates.

74 DETIENNE, op. cit., p. 132.

75 DETIENNE, op. cit., p. 135. 
¿Es posible detectar el punto en que surgen estas incapacidades y limitaciones que la teoría presenta para dar cuenta de hechos que están ahí y que incluso se resisten tercamente a ese esquematismo explicativo?

Metodológicamente nos parece que hay varias cosas que objetar tanto a Colli como, sobre todo, a Detienne, todas ellas conectadas íntimamente entre sí: una primera objeción sería la tendencia excesivamente rígida a situar las cosas en la perspectiva de la causalidad lineal, situando las distintas manifestacionex culturales en un rígido antes y después; una segunda objeción sería la confusión, implícita en todo el planteamiento, entre síntomas, indicios, resultados y causas o motivos de los mismos; y aún podría plantearse una tercera objeción que, desde una perspectiva global, abarcaría por igual a las demás: ¿había ahí algo tan radicalmente chocante como para exigir una explicación, o el problema nace en realidad de la conceptualización a posteriori de los hechos?

No es posible entrar aquí a fondo en lo que esas objeciones sugieren, de modo que nos limitaremos a un leve desbroce de la cuestión.

De hecho, todo lo que aquí se ha venido examinando pertenece al orden de los síntomas, indicios, resultados. Es decir, nos explicitan momentos distintos de estados de pensamiento, en evolución o cambio. Pero, como bien nos señalaba ya antes Detienne, "la historia de las ideas no es nunca "su propio principio de inteligenciar. Para que emerjan tales cuestiones... es preciso que se haya consumado la ruina de un sistema de pensamiento...." ${ }^{76}$. Ahora bien, si el estado de las ideas en un determinado contexto no es su "propio principio de inteligibilidad», hay que explicar más bien entonces cómo se consuma "la ruina de un sistema de pensamiento", que es lo que propicia la aparición de las nuevas ideas. La pregunta a formular es, pues, cómo se arruina un sistema de pensamiento.

Pero ¿qué es un sistema de pensamiento? ¿Existe como tal en el medio en que el historiador lo sitúa o es más bien la representación que este se hace de la situación a partir de un conjunto de datos? De una manera más concreta: ¿̨ónde comienza la racionalidad de la sofística y de la filosofía y dónde termina la pre-racionalidad del mito? ¿O es la pregunta ya una manera de presuponer lo que habría primero que probar?

Ni el mito está tan falto de racionalidad, ni las nuevas manifestaciones culturales son tan racionales como se pretende. Una de las razones de la perviven- 
cia y funcionalidad del mito es seguramente su flúida plasticidad. La pervivencia del mito - y, en su estela, de la palabra eficaz o mágico-religiosa - se debe a su ambigüedad semántica. La difuminación de los contornos, el estar siempre orlado por la significación contraria, el poderse decantar por más de una opción semántica, hace del símbolo mítico un instrumento adecuado al quehacer de la vida. El ser humano precisa representaciones de mundo para sobrevivir. Pero no vive en sus representaciones ni por ellas; vive de la capacidad que ellas muestran para orientar su pervivencia. Y, a su vez, el mundo no es sus representaciones, por más que estas nos ofrezcan parámetros de referencia sobre lo que hay.

Por otra parte, suponer que nuestra conciencia reflexiva es el lugar natural de todas nuestras operaciones mentales es una pura ilusión, que no refrenda la más elemental experiencia. Un innato software aún no explicado pone a disposición de la conciencia resultados de cuya gestación no hemos sido conscientes. Sin esto no habría pensamiento. En ese espacio propiamente preconsciente se conserva todavía una buena dosis de sensibilidad realista - toda vida es «un realista hipotético", como decía K. Lorenz-. Es decir, los mecanismos de ajuste funcionan ahí mejor, en bucle constante con la experiencia. Con ello nuestras representaciones de mundo van siendo sutilmente diferenciadas y matizadas, incluso hasta llegar a ser otra cosa. Lo que, en el fondo, arruina un modo de pensar es su ineficacia vital y existencial.

Llama la atención que Detienne, luego de insistir tanto en que lo diferencial de ese pensar mágico-sagrado es la ambigüedad, y luego de dejar constancia de que coexistieron con él instituciones de palabra-diálogo como la de la sociedad de los guerreros, no intuyera que eso significa ni más ni menos que las que él considera formas definitorias de un estado cultural eran sólo parte de la realidad; es decir, que esta era más plural y compleja, más «ambigua», de lo que sus documentos daban a entender. $Y$ eso no significa tomar estos como desinformados: el desinformado ha sido el lector que los ha tomado como testimonio único o, en todo caso, más valioso. ¿Y si en realidad la conciencia simbólica de una cultura - la que se nos da escrita e idealizada en su literatura y en sus ritos- estuviera constituida no por aquello que ella ya era, sino más bien por lo que aspiraba a ser, sin serlo del todo o apenas?

Si ni el mito está tan falto de racionalidad como se pretende, ni otros modos alternos de pensamiento son tan absolutamente racionales, el problema debió plantearse de otra manera: ‘a qué se debe que se produzca un relevo de modos de racionalidad, al menos en el nivel de lo que se promulga como pensamiento «ideal»? 
El mito tiene una función. Más existencial que teórica. En su polivalencia está su gran valor de adaptación. La racionalidad reflexiva, por su parte, desarrolla una capacidad crítica de alguna manera autónoma: nace de una reflexión sobre el uso del lenguaje visto en sí mismo. La sustitución de un modelo por otro no significa de suyo un paso lineal del "mito al logos», sino más bien la puesta a prueba de un nuevo modelo. Que el que ha logrado imaginar ese modelo lo considere mejor y aun exclusivo puede formar parte de las limitaciones de la racionalidad humana, no necesariamente de su excelencia. Ese nuevo modelo se sitúa a la sombra del Logos. Pero el Logos, a su vez, opera con aura de mito. Cuando el modelo explicativo physis de los milesios resulta en exceso estrecho para dar cuenta de las inquietudes sociales y humanas, es el Logos el que toma el relevo. Acuñado en la forja de la reflexión sobre el lenguaje y sus posibilidades expresivas, el Logos asume la tarea de dar cuenta por sí mismo de todo. Que el todo haya de atenerse a las pautas y reglas de ese Logos es un a priori: lo que hay no sabe nada de esa racionalidad emergida. Ni es parte de ella ni se opone a ella: se deja decir por ella.

¿Qué relación hay entonces entre Mito y Logos? Es una relación de alternancias ocultas. El mito es el puerto a que se acoge la razón cuando sus pretensiones fracasan. No hay una frontera - y menos una aduana - entre ambas zonas. Con mucha frecuencia los filósofos usan los conceptos de la filosofía como verdaderos «mitemas», es decir, como conceptos/términos inmediatamente efectivos. Despojados ya del humus que los nutrió, como verdaderos talismanes de la inteligencia y la profundidad, su uso tiene realmente poco de racionalidad estricta. En el contexto de la filosofía clásica —y bastante más allá de ella—, el «Logos» viene a ser, con harta frecuencia, un nuevo «mito». El proceso que está ahí en juego es algo absolutamente quebrado y recesivo: un concepto o una idea arruinan un mitema en vigor; y a su vez operan como un mito hasta que la crítica racional/razonable lo pone de nuevo en tela de juicio. Es la historia misma de la filosofía. Si abandonamos esta mecánica, entramos en la racionalidad pura y mitificada: en el «Mito del Logos».

El pensamiento primitivo griego está prendido en esa profunda e inevitable bivalencia: la relación entre mito y logos es un movimiento pendular y a la vez cuasi circular. Todo momento crítico y racional viene a recaer en un tiempo mítico o mitificante: el de la fe sin resquicios en la operatividad de los conceptos previamente acuñados, sin tener ya en cuenta su contexto semántico de origen. Esto - y sólo esto- explica la impureza radical de los planteamientos de toda filosofía, siempre a caballo entre una critica racional/razonable y una diviniza- 
ción implícita de la propia racionalidad. El gran problema de la racionalidad es, en última instancia, su necesidad de afirmarse como autónoma ignorando de dónde viene.

Y sólo esto permite entender que, en pensadores claramente tan orientados a la exploración de lo dado como puede ser Aristóteles, coexistan elementos heterogéneos y contradictorios. Para no decir nada de Platón, en quien el hecho es dominante. Esto es lo que hace posible que, en el contexto de la filosofía, se dé una tenaz pervivencia de mitemas en el corazón mismo del tejido de la racionalidad. La racionalidad humana nunca es algo químicamente puro.

Tomemos, p. e., la cuestión del carácter «oculto» de la verdad o de su trascendencia respecto del lenguaje. El tono místico-visionario de la "verdad" es constante en Platón. Baste ahora una muestra: "Por mi parte, al menos, no hay ni habrá ciertamente nunca escrito alguno sobre semejantes temas. Pues un conocimiento de tal indole no podría ser comunicado por medio de palabras..."77. Y no ocurre otra cosa en Aristóteles, aunque ello se dé sobre todo en sus escritos de juventud. ¿Dónde queda el antecesor del noûs sino en la mántica extática? Esto es lo que el filósofo había escrito en el Sobre la Filosofia. "Aristoteles afirmaba que, en los hombres, la noción de los dioses emana de dos principios... En primer lugar, de lo que ocurre en lo que concierne al alma, a causa de la aparición -en los sueños- de arrobamientos del alma y a causa de las adivinaciones. Pues, dice el, cuando en los sueños el alma se presenta por si misma, entonces, reencontrando su propia naturaleza, predice y profetiza las cosas futuras" 78 . Más aún, si se quiere: "La intuición de lo inteligible, de lo no mezclado y de lo sagrado, que ilumina al alma de parte a parte como un rayo, permite en cierto momento tocar y contemplar por una sola vez: por eso tanto Platón como Aristóteles llaman a esta parte de la filosofia la iniciación suprema (epoptikón)...»79. La propia "fulguración noética» es referida a un contexto mistérico - mas exactamente a la experiencia cognitiva de Eleusis 80 - en Sobre la Filosofia: "... Lo que es competencia de la enseñanza y lo que es competencia de la iniciación. La primera cosa alcanza en verdad al hombre por la mediación del oido, la segunda por el contrario es alcanzada cuando la propia capacidad intuitiva (noûs) es iluminada. Lo que Aristóteles llamó

77 Platón, Carta VII, $341 \mathrm{c}-\mathrm{d}$.

78 ARISTÓteles, Sobre la Filosofla, Frag. 12a, Ross.

79 ARISTOTEles, Eudemo, Fr. 10, Ross. La expresión «tocar» - thigontes- aparece igualmente en Metafisica, Theta 10, 1051b 24. Y ver ibid., $1072 \mathrm{~b} 21$.

80 CoLL, op. cit., p. 385. 
exactamente un estado mistérico, semejante a las iniciaciones de Eleusis (en estas, en efecto, el iniciado era formado por medio de visiones, no sometido a una enseñanza) „81. ¿Y no es un principio clave de toda su metodología filosófica el de que el conocer humano procede de "lo más cognoscible para nosotros a lo más cognoscible en sit? ¿Es esto otra cosa que mantener la idea, ya heraclitiana, de que la «armonía oculta es mayor que la visible» o de que «la naturaleza gusta de ocultarse»? Tomar como "oculto" y misterioso lo que o bien aparece en la conciencia sin que ella haya sido testigo privilegiado de su gestación, o bien no está simplemente en lo que hay - porque las representaciones que nos hacemos del mundo no están en el mundo-, es recurrir a lo que llamamos mitificación, cuando no afecta a nuestro propia manera de pensar. La diferencia está en el sujeto que juzga.

La secuencia entre sophia y philosophia no es, pues, lineal. Como tampoco lo es la transición del presunto mythos al presunto logos. Hay transiciones en modos distintos de la racionalidad. Hay razonable racionalidad en los dominios del mythos. Y hay mitificaciones en los dominios del logos. Nos movemos constantemente entre ambos registros. Sin una concepción de cómo funciona realmente nuestra mente, todo intento de explicación de la historia de la filosofía en meros términos conceptuales está llamado al fracaso. Obedece a una subrepticia mitificación de nuestra razón.

81 ARISTOTElES, Sobre la Filosofla, Fr. 15. No se olvide que el paradigma de enseñanza era, para Aristóteles como para los griegos en general, el de la transmisión hablada/oída. 